\title{
RÉGIMEN JURÍDICO DE LA SITUACIÓN ADMINISTRATIVA DE SEGUNDA ACTIVIDAD: UNA PERSPECTIVA IUSLABORALISTA*
}

\author{
Legal Regime of the Administrative Situation of Second Activity: \\ a Labour Law Perspective
}

\author{
Francisco Miguel Ortiz González-Conde \\ Doctor en Derecho del Trabajo y de la Seguridad Social \\ Universidad de Murcia
}

\section{ABSTRACT}

Se entiende por situación administrativa de segunda actividad aquella consistente en la reubicación de la persona funcionaria en otro puesto de trabajo distinto en razón de sus aptitudes psicofísicas, salvaguardándole las condiciones salariales, de antigüedad, o de expectativa de pensión que viniese disfrutando. Su regulación no cuenta con una normativa uniforme ni homogénea, constituyendo una particularidad en el régimen de determinados cuerpos de las Administraciones Públicas. Este trabajo se centrará en destacar las dificultades de su aplicación, las incoherencias derivadas de sus distintas configuraciones, asi como su relación con medidas de protec-

* El presente trabajo se enmarca en el Proyecto de Investigación DER2016-76557-R, sobre «El futuro del sistema español de protección social: análisis de las reformas en curso y propuestas para garantizar su eficiencia y equidad V: salud, familia y bienestar», financiado por el Ministerio de Economía y Competitividad, e incluido en la Convocatoria 2016 de Proyectos I+D+I, correspondientes al Programa Estatal de Investigación, Desarrollo e Innovación orientada a los Retos de la Sociedad. 
ción social, en una institución juridica a medio camino entre el Derecho Administrativo y el Derecho del Trabajo.

Palabras clave: situación administrativa, segunda actividad, trabajo peligroso.

The administrative situation of second activity consists in the relocation of the civil servants to a different occupation due to their psychophysical abilities, safeguarding the conditions of salary, seniority at work or expectation of pension. Its regulation does not have a uniform or homogeneous regulation, but on the contrary it is a peculiarity in the personnel regime of each Public Administration. This paper will focus on highlighting the different possible options as well as the inconsistencies resulting from its application and its relationship with social protection, in a legal institution halfway between Administrative Law and Labor Law.

Keywords: administrative situation, second activity, dangerous work. 


\section{SUMARIO}

1. Introducción. 2. Régimen jurídico de la situación administrativa de segunda actividad. 2.1. Naturaleza jurídica de la situación administrativa de segunda actividad. 2.2. Ámbitos objetivos y subjetivos de la situación administrativa de segunda actividad. 3. Perspectivas desde la protección social. 3.1. El encuadramiento. 3.2. El pase de la situación de segunda actividad a la jubilación mediante el anticipo de la edad ordinaria de retiro. 4. Limitación en el acceso a los cuerpos funcionarios provistos de segunda actividad. 5. Comparativa a nivel estatal del régimen jurídico de segunda actividad y reserva. 6. Conclusiones. 7. Bibliografía.

\section{Introducción}

El presente trabajo pretende revisar el régimen jurídico de la situación administrativa de segunda actividad para el personal funcionario, aplicable únicamente a ciertos puestos de trabajo que por su propia naturaleza solo pueden ser provistos por funcionarios específicos, como aquellos que conllevan el ejercicio de autoridad. En este sentido, la perdida de la idoneidad psicofísica necesaria para afrontar los altos requerimientos que comportan las tareas a realizar, ya sea por una merma en las capacidades motivada por una declaración de incapacidad o la pérdida de idoneidad de las condiciones psicofísicas motivadas por la incidencia biológica del transcurso del tiempo, suponen un problema en cuanto a la situación jurídica de este personal funcionario.

A través de las siguientes páginas se procura enfocar el estudio de esta institución propia del Derecho Administrativo, combinándola con una perspectiva iuslaboralista, pues, a tenor de los incrementos anuales de la edad de jubilación que transitoriamente se están llevando a cabo por el Real Decreto Legislativo 8/2015, de 30 de octubre, por el que se aprueba el texto refundido de la Ley General de la Seguridad Social (en adelante, LGSS), pretender mantener en servicio activo a estos profesionales hasta tales edades conlleva incongruencias normativas que se transforman en deficiencias de personal o servicio ${ }^{1}$.

\footnotetext{
1 Sobre la drástica reducción del empleo público permanente producida en los últimos tiempos y sus consecuencias, puede verse López (2017).
} 
El interés por la situación de segunda actividad se ha reavivado con la desaparición del Régimen de Clases Pasivas del Estado, mediante el Real Decretoley 13/2010, a partir del 1 de enero de 2011, pues desde entonces prácticamente la totalidad de estos cuerpos de funcionarios (estatales, comunidades autónomas y locales) causan alta en el Régimen General de la Seguridad Social (en adelante, RGSS), al tiempo que paradójicamente, cada uno de ellos cuenta con un régimen de personal y de segunda actividad propio.

Igualmente, conviene también reflexionar acerca de la edad como un intervalo de mínimos y máximos, porque del mismo modo que los requerimientos físicos constituyen una condición imperativa de acceso y permanencia en estos cuerpos, el deterioro derivado del cumplimiento de una determinada edad en los aspirantes constituirá otro proceso paralelo, que repercutirá en el tiempo efectivo de carrera de servicio y, por tanto, de cotización de los futuros miembros. En un extremo se sitúa la rebaja de edad de retiro para estos colectivos (para ello se reconstruye el iter político y parlamentario de este tipo políticas) y, en otro extremo, la legalidad en el establecimiento de límites máximos de edad para el acceso a estos cuerpos de función pública.

$\mathrm{Al}$ respecto se han pronunciado en repetidas ocasiones durante los últimos años tanto el Tribunal Supremo como el Tribunal de Justicia de la Unión Europea, sobre cómo debe contemplarse esta limitación a partir de las exigencias del principio de igualdad y la interdicción de medidas discriminatorias en función de circunstancias personales (art. 14 CE y art. 23.2 CE) y Directiva 2000/78/CE.

\section{Régimen jurídico de la situación administrativa de segunda actividad}

\subsection{Naturaleza jurídica de la situación administrativa de segunda actividad}

Se entiende por segunda actividad la reubicación de la persona funcionaria en un puesto de trabajo distinto en razón de sus aptitudes psicofísicas, salvaguardándole las condiciones salariales, de antigüedad, o de expectativa de pensión que viniese disfrutando, al no extinguirse la relación de servicios, sino tan sólo la relación orgánica (Entrena, 1995: 279).

Se trata de una situación administrativa específica al ser propia de las Fuerzas y Cuerpos de Seguridad por su exposición particular a situaciones de riesgo y peligrosidad. Todas las leyes sobre régimen personal de policías o leyes autonómicas de coordinación de policías municipales contemplan en la actualidad dicha situación administrativa, cuyo carácter peculiar les viene otorgado por tratarse de un intento de las Administraciones por compaginar la inamovilidad de los funcionarios hasta su jubilación con la capacidad física que requieren las funciones de policía. 
Ahora bien, lo que no queda tan claro es el criterio empleado por cada legislador autonómico para delimitar la naturaleza jurídica de la situación administrativa de segunda actividad, siendo en unas ocasiones considerada como una situación administrativa especial y en otras como una modalidad de servicio activo $^{2}$.

De un lado, es concebida como una situación administrativa especial al tratarse de una modificación de la relación funcionarial, debida a la concurrencia de circunstancias objetivas o subjetivas, que comportan alteraciones de la estructura básica de la misma, con los efectos que las respectivas normas establecen para cada una de ellas (Palomar, 2006: 23). En este sentido, se puede decir que la situación administrativa especial de segunda actividad presenta un carácter tuitivo del funcionario público al proteger su aptitud psicofísica, al tiempo que evita durante el desempeño de sus funciones, en caso que esta aptitud falte o sea insuficiente, cause riesgos al propio funcionario que la padece, a sus compañeros y a los ciudadanos en general (Bastardo, 2004: 3927).

Así, por ejemplo, la referencia en la materia la constituye el art. 1 Ley 26/1994, de 29 de septiembre, por la que se regula la situación de segunda actividad en el Cuerpo Nacional de Policía, que establece la segunda actividad como una situación administrativa especial de los funcionarios del Cuerpo $\mathrm{Na}$ cional de Policía (excluyendo a quienes ocupen plazas de facultativos y técnicos), que tiene por objeto fundamental garantizar una adecuada aptitud psicofísica mientras permanezcan en activo, asegurando la eficacia en el servicio. Con el mismo tenor literal se configuran casi la totalidad de las normativas autonómicas $^{3}$.

De otro lado, también puede ser concebida como una modalidad de situación administrativa en activo. En este sentido, el art. 23.1 de la Ley de Coordinación de Policías locales de Castilla-La Mancha 8/2002, de 23 de mayo, la identifica como modalidad de la situación administrativa de servicio activo cuyo objeto es garantizar una adecuada y permanente aptitud psicofísica, pero en ningún momento alcanza a definirla (Bastardo, 2004: 3927).

A este tenor, se podría razonar que, en tanto que situación administrativa especial, no aparece expresamente mencionada en el título VI (del art. 85 al art. 92) sobre las situaciones administrativas previstas por del Real Decreto Legislativo 5/2015, de 30 de octubre, por el que se aprueba el texto refundido de la Ley del Estatuto Básico del Empleado Público (en adelante, EBEP). Este contexto podría servir como justificación para incardinar su fundamento jurídico dentro del servicio activo, pues a diferencia de las situaciones con sustantividad

\footnotetext{
2 Trayter (2016: 187-189) ofrece una visión de derecho comparado desde Francia, Reino Unido y Bélgica.

3 Almonacid (2005: 4057) recopila y revisa toda la normativa autonómica.
} 
propia recogidas en el art. 85 EBEP (servicio en activo; servicios especiales; servicio en otras Administraciones Públicas; excedencia y suspensión de funciones), que despliegan efectos en la concreta relación de servicio del funcionario, tal situación no ocurre para la situación de segunda actividad, que con la salvedad de las funciones concretas a desempeñar, no logra distinguirse del servicio en activo (Blanco, 2014: 3).

En cualquier caso, no se puede olvidar que con la aprobación (y reciente refundición del EBEP) la regulación de las situaciones de actividad presenta un carácter bastante amplio al permitir que las leyes de la función pública que se dicten en su desarrollo regulen otras situaciones administrativas $^{4}$, ya sea en razón de razones organizativas, de reestructuración interna, de asignación de puestos de trabajo, de cesación en el servicio activo, etc. y máxime en comparación con las regulaciones precedentes (Parada y Fuentetaja, 2015: 302).

El hecho de que la normativa autonómica y local intente continuamente buscar referencias en la normativa estatal del EBEP y la Ley Orgánica 2/1986, de 13 de marzo, de Fuerzas y Cuerpos de Seguridad (en adelante, LOFCS) puede ser un indicador sobre la necesidad de equiparación de condiciones entre cuerpos, aunque, la comparación no siempre devuelve como respuesta un reflejo perfecto.

Con ello se quiere decir, que si bien es posible pretender una regulación unitaria para todos los cuerpos, al entender que estamos ante una materia de contenido netamente básico (Gil, 2014: 647) y por ende debería ser objeto de una intervención estatal específica, como el Reglamento contemplado en la Disposición final 3.a de la Ley 7/1985, de 2 de abril, Reguladora de las Bases del Régimen Local (en adelante, LRBRL), (así, por ejemplo, la propuesta para una regulación homogénea de la segunda actividad entre el cuerpo de Mossos d'Esquadra y el cuerpo de Bomberos de la Generalitat ${ }^{5}$ ), igualmente es posible descartar la posible equiparación entre cuerpos, no ya por respeto al principio de autonomía local, sino en atención a las propias funciones que el ordenamiento jurídico atribuye a cada cuerpo, siendo las de unos más eminentemente operativas y más

4 El inicial Decreto 315/1964, de 7 de febrero, por el que se aprobaba el texto articulado de la Ley de Funcionarios Civiles del Estado fue reemplazado por la Ley 30/1984, de 2 de agosto, de medidas para la reforma de la Función Pública, y ésta a su vez reemplazada por la Ley 22/1993, de 29 de diciembre, de medidas fiscales, de reforma del régimen jurídico de la función pública y de la protección por desempleo y el Real Decreto 365/1995, de 10 de marzo, por el que se aprueba el Reglamento de Situaciones Administrativas de los Funcionarios Civiles de la Administración General del Estado.

5 Proposición de Ley de regulación de la segunda actividad, de aplicación a los cuerpos de bomberos de la Generalitat de Catalunya, de Mossos d'Esquadra y de las policías locales de 13 de julio de 2015, citada en Trayter (2016: 185) 
arriesgadas y penosas, que en otros (también las diferencias en cuanto régimen de protección social $\left.{ }^{6}\right)$.

Aunque, a estas alturas, nada hay de extraño o novedoso en estas propuestas, pues la situación administrativa de segunda actividad se presenta como una regulación común a todos los Cuerpos policiales, tanto autonómicos como locales, en el País Vasco y Navarra, como más adelante se detallará.

\section{2. Ámbitos objetivos y subjetivos de la situación administrativa de segunda actividad}

En relación a la segunda actividad de los cuerpos autonómicos y municipales, las leyes autonómicas de coordinación contemplan como ámbito objetivo de aplicación, para sus respectivos cuerpos de policías autonómicos y locales, los motivos de edad o inadecuación de las facultades psíquicas o físicas necesarias para el ejercicio de sus funciones ${ }^{7}$. El reconocimiento de esta situación requiere que el funcionario esté en activo.

Como puede intuirse, especialmente para el caso de los cuerpos de policías locales, no son muchas las opciones prácticas con que cuentan los Ayuntamientos para materializar la situación de segunda actividad, pues, a pesar de tratarse de una decisión dentro del ámbito de su autonomía local, su reconocimiento está condicionado, por un lado, a estas mismas normas de coordinación surgidas al amparo del art. 39 LOFCS y, por otro, a la existencia de vacantes $^{8}$, ya sean por disponibilidad de plazas dentro del mismo cuerpo, o bien otras del mismo Ayuntamiento ${ }^{9}$, o en su defecto, la posibilidad de segunda actividad sin destino, lo que en la práctica equivaldría a experimentar una jubilación efectiva, aunque administrativamente el funcionario permanezca en activo (Serrano, 2001: 2172).

Existen corporaciones locales con reducido volumen de funcionarios que no se han planteado esta problemática hasta surgida la cuestión por motivos de edad de su personal, es decir, no todos los municipios cuentan en la Relación

${ }^{6}$ STS 23 mayo 2008, núm. 3056.

7 La STSJ-Comunidad Valenciana de 24 julio 2009, Contencioso-Administrativo, declara que no puede admitirse únicamente como la declaración de invalidez total y absoluta como la única causa de jubilación de los funcionarios de la policía local por razón de pérdida de aptitudes para el desempeño de las funciones propias asignadas a su puesto, sino que basta su incapacidad permanente, siendo excepcional el pase a la situación de segunda actividad.

8 STS 8 junio 2009, núm. 4122

9 Cabe recordar que el art. 169 RD Legs. 781/1986, de 18 de abril, texto refundido de las disposiciones en materia de Régimen Local, que permite el establecimiento de normativa adecuada para que los puestos de trabajo atribuidos a la subescala de Subalternos de Administración General, puedan ser desempeńados por funcionarios de Servicios Especiales que, por edad u otras razones, tengan disminuida su capacidad para misiones de particular esfuerzo o penosidad, pero que conserven la requerida para las tareas de Subalterno. 
de Puestos de Trabajo (RPT) con un catálogo de puestos de destino calificados como de segunda actividad, lo que en primer lugar supone, además de una irregularidad, una incongruencia, pues sin RPT no es posible el puesto de trabajo, ¿cómo se va a cubrir lo que no existe? Y en segundo lugar, esos puestos de trabajo, que se han de crear en la RPT, tienen que ser provistos por estos funcionarios y no por otros, es decir, el puesto de trabajo es singularizado, individualizado, específico o concretado dentro de la RPT (Pérez, 2005: 139).

Esta situación, añadida a las minoraciones retributivas que podría suponer el pase a segunda actividad, conlleva en la práctica el mantenimiento del personal en servicio activo hasta alcanzar la edad de pase forzoso a jubilación, con el consecuente envejecimiento de la plantilla, y paralización de la oferta de empleo público en la Policía Local, que no se llevará a cabo en tanto no se produzcan las bajas correspondientes en dichos Cuerpos (González, 2002: 2309).

En relación a los cuerpos de policías autonómicos, para la Policía Foral Navarra, a través del art. 47 de la Ley Foral 8/2007, de 23 de marzo ${ }^{10}$, se establece que la edad en ningún caso podrá ser inferior a 55 años. La movilidad se producirá por este orden, dentro del cuerpo al que pertenezcan, en otras policías de Navarra, siempre que se hubieran suscrito los oportunos convenios de colaboración entre las administraciones respectivas, y en puestos de trabajo de la misma Administración de la que dependan, que estén relacionados directamente con la formación, políticas de seguridad u otras, o con actividades de policía administrativa ${ }^{11}$.

El régimen de retribuciones estará conformado por las retribuciones básicas correspondientes a la categoría y las de carácter personal que se tuvieran reconocidas, además de las complementarias del puesto de trabajo que efectivamente se ocupe. No obstante, si las retribuciones básicas y complementarias del nuevo puesto fueran inferiores a las que se percibieran en el momento del pase, la persona funcionaria tendrá derecho a percibir un complemento personal transitorio cuya cuantía será igual a la diferencia.

La regulación de la Ertzaintza es algo más confusa, pues a través del art. 85 de la Ley 4/1992, de 17 de julio, de Policía del País Vasco ${ }^{12}$, se prevé el pase a segunda actividad a partir el cumplimiento de la edad que se determine por Ley del Parlamento Vasco para cada categoría y, a continuación, el art. 87 ha-

10 BON núm. 40 de 2 de abril de 2007 y BOE núm. 100 de 26 de Abril de 2007. Recientemente se ha aprobado una modificación de la Ley de Policía Navarra, Ley 15/2015 (BON núm. 71 de 15 de abril de 2015).

11 Art. 47.2.c) en su sentido más amplio, en el ámbito de las competencias de dicha Administración, tales como labores auxiliares en la tramitación de expedientes sancionadores, tareas administrativas o ejecutivas, vigilancia, control, inspecciones y otras, siempre que sean adecuados a su nivel y conocimientos y requieran menor esfuerzo físico, peligrosidad o dificultad

12 En la actualidad se está trabajando en un anteproyecto de modificación de la misma 
bla del pase a la situación de segunda actividad reglamentariamente establecida. Las previsiones normativas fueron desarrolladas por el Decreto 7/1998, revisado por el Decreto 201/2012 13 , y entre medias, el Decreto 194/2012, de 9 de octubre, que aprueba el Acuerdo regulador de las condiciones de trabajo del personal de la Ertzaintza para los ańos 2011, 2012 y 2013, que establecen la edad en 56 años.

No obstante, conforme al art. 85 Ley 4/1992, se excluye del pase a la situación de segunda actividad al personal funcionario que pertenezca a la Escala de Facultativos y Técnicos de la Ertzaintza. Al ser el único cuerpo con previsión de jubilación anticipada, cuando la solicitud sea de instancia de parte, el art. 17 bis del Decreto 7/1998 prevé el compromiso de acogerse a la jubilación voluntaria al alcanzar la edad de 60 años o, en su caso, 59 años, de conformidad con lo dispuesto, entonces, en la DA 47a LGSS, salvo que no cumpla los requisitos necesarios para percibir una pensión equivalente al 100 por 100 de la base reguladora.

Respecto de las percepciones salariales, este es el cuerpo que disfruta de mayores garantías, pues se prevé que se mantenga, junto al salario base, el complemento de destino y el complemento específico general de la categoría de pertenencia y los de carácter personal que se tuvieran reconocidos, incluidos los que correspondan en concepto de trienios, que continuarán perfeccionándose en dicha situación, al tiempo que se percibirá el complemento específico singular que se asigne en virtud de las funciones y tareas que se deban desarrollar, derivadas de las limitaciones funcionales que determinaron el pase a tal situación que, en ningún caso, será inferior al establecido para la categoría de agente de seguridad ciudadana.

La segunda actividad de los Mossos d'Esquadra viene regulada en el art. 61 Ley 10/1994, de 11 de julio, de la Policía de la Generalidad de Cataluña "Mossos d'Esquadra» ${ }^{14}$, desarrollada por el Decreto 246/2008, de 16 de diciembre, de regulación de la situación administrativa especial de segunda actividad en dicho cuerpo. El acceso a la segunda actividad por razón de la edad no puede ser inferior a 57 años y, a diferencia de la Ertzaintza, está permitido el pase al personal funcionario que ocupe puestos facultativos y técnicos.

La movilidad se producirá dentro del mismo cuerpo o en puestos pertenecientes a otros cuerpos de la Generalidad que sean adecuados a su nivel y conocimientos, conservando las retribuciones correspondientes a la categoría y las de carácter personal que tenían reconocidas, además de las complementarias del nuevo puesto de trabajo que se ocupe. En el supuesto de que las retribuciones totales sean inferiores a las que se percibían en el momento de pasar a la se-

\footnotetext{
13 BOPV núm. 155 de 11 de Agosto de 1992 y BOE núm. 39 de 15 de febrero de 2012

14 DOGC núm. 1923, de 20 de julio de 1994, y BOE núm. 192, de 12 de Agosto de 1994.
} 
gunda actividad, se recibirá un complemento personal transitorio que iguale las retribuciones con las que se percibían anteriormente.

En cuanto a la segunda actividad en la Policía Canaria, los arts. 53 y 54 de la Ley 2/2008, de 28 de mayo, del Cuerpo General de la Policía Canaria ${ }^{15}$, y los arts. 60 y siguientes del Decreto 77/2010, de 8 de julio, por el que se aprueba el Reglamento de organización y funcionamiento del Cuerpo General de la Policía Canaria, establecen que el pase a la actividad se producirá a los 57 ańos, o bien a los 63 ańos cuando se trate de segunda actividad sin destino. Las actividades de destino estarán dentro del mismo cuerpo, o bien corresponderán a un puesto de trabajo de la Administración de la Comunidad Autónoma, adecuado a su experiencia y capacidad, según se determine reglamentariamente. Y en cuanto al régimen retributivo, la situación de segunda actividad no supondrá disminución de las retribuciones básicas y complementarias, salvo aquellas que se encuentren vinculadas al puesto de trabajo o destino concreto que se desempeñe.

Para todos los cuerpos autonómicos, el período de tiempo que se permanezca en la situación de segunda actividad será computable a efectos de antigüedad y derechos pasivos, en el empleo que se poseía en el momento de producirse el paso a dicha situación.

En relación a los cuerpos de policías municipales, como funcionarios de la administración local, están sujetos a las disposiciones comunes para el personal al servicio de las entidades locales establecidas en la Ley 7/1985, de 2 de abril, Reguladora de las Bases del Régimen Local. No obstante, la fundamentación jurídica de este cuerpo hay que buscarla en el art. 52.1 LOFCS, donde se dispone que los Cuerpos de Policía Local son:

institutos armados, de naturaleza civil, con estructura y organización jerarquizada, rigiéndose, en cuanto a su régimen estatutario, por los principios generales de los $\mathrm{Ca}$ pítulos II y III del Título I y por la sección cuarta del Capítulo IV del Título II de la presente Ley, con la adecuación que exija la dependencia de la Administración correspondiente, las disposiciones dictadas al respecto por las CCAA y los Reglamentos específicos para cada Cuerpo y demás normas dictadas por los correspondientes Ayuntamientos.

No obstante, no existe en la actualidad una normativa específica, estatutaria o de régimen común para los aproximadamente 540 cuerpos y 60.000 efectivos.

Por cuanto respecta a su régimen de segunda actividad, la mayoría de comunidades autónomas han extendido el beneficio de segunda actividad también a los policías locales en los ayuntamientos en ellas comprendidos, con el objetivo de coordinar los distintos cuerpos mediante textos para la coordinación de la po-

15 BOC núm. 109, de 3 de junio de 2008. 
licía local. Como consecuencia el marco jurídico se dualizó, pues para aquellas que no la habían regulado resultaba de aplicación la legislación estatal supletoria, aunque en otros casos, algunas que lo hicieron, llegaron a invadir competencias estatales, dando lugar a conflictos ante la jurisdicción ${ }^{16}$. Sobre la coordinación se ha de tener presente el criterio manifestado en la STC 27 febrero 1987, núm. 27 donde se afirmó que:

la coordinación implica la fijación de sistemas de relación que hagan posible, además de la información recíproca la homogeneidad técnica y la acción conjunta de las administraciones coordinadora y coordinada, evitando las disfunciones que produciría la gestión separada de los servicios públicos con incidencia en diversos ámbitos de intereses relacionados entre sí. Pero no puede traducirse en la emanación de órdenes concretas que prefiguren exhaustivamente el contenido de la actividad del ente coordinado, agotando su propio ámbito de decisión autónoma; en cualquier caso, los medios y técnicas de coordinación deben respetar un margen de libre decisión o de discrecionalidad en favor de las Administraciones sujetas a la misma, sin el cual no puede existir verdadera autonomía.

A título de ejemplo, el art. 34 de la Ley 4/1998, de 22 de julio, de coordinación de Policías Locales de la Región de Murcia ${ }^{17}$, actualmente en proceso de reforma ${ }^{18}$, declaró genéricamente que en ningún caso el pase a la segunda actividad será a una edad inferior a 55 ańos; y el art. 31.1 de la Ley andaluza 13/2001, de 11 de diciembre, de Coordinación de las Policías Locales ${ }^{19}$, prevé que el pase a la situación de segunda actividad por edad tendrá lugar al cumplirse 60 años en la escala técnica, 57 años en la escala ejecutiva o 55 años en la escala básica.

En el ámbito de los Ayuntamientos murcianos, estas previsiones se desgajan de manera singular. Siguiendo con el ejemplo, y en base a un criterio de elección azaroso, para el municipio de Águilas, el art. 4 del Reglamento de Segunda Actividad de la Policía Local de Águilas ${ }^{20}$, detalla, más allá de la Ley de coordinación, que a petición de la persona interesada o de oficio, el paso a la segunda actividad será al cumplir las edades de 62 años en la escala técnica, 60 años en la escala ejecutiva, y 55 años en la escala básica. También el municipio de Yecla detalla las

16 STC 16 enero 2003, núm. 1.

17 BORM núm. 169, de 24 de julio de 1998.

18 El Borrador del Anteproyecto de Ley de Coordinación de las Policías Locales de la Comunidad Autónoma de la Región de Murcia, publicado por la Consejería de Presidencia a fecha 1 enero de 2016, contiene novedades sobre el pase a segunda actividad por motivos de edad: a los 60 años para la escala superior o cuando les resten cinco años para alcanzar la edad obligada de jubilación, 58 años para la Escala Ejecutiva, o cuando les resten seis años para alcanzar la edad obligada de jubilación, y 55 años para la Escala Básica y de Subinspección, o cuando les resten siete años para alcanzar la edad obligada de jubilación. Además, se amplía el catálogo de puestos de destino.

19 BOJA núm. 144 de 15 de diciembre de 2001.

20 BORM núm. 123 de 30 de mayo de 2014. 
edades de segunda actividad a través de escalas; así, el art. 10 del Reglamento de Segunda Actividad de la Policía Local de Yecla ${ }^{21}$, establece distintos baremos: para la escala técnica y ejecutiva, 61 años, y 59 años para la escala básica.

Haciendo una comparativa con otros Ayuntamientos del sur peninsular, dentro de la provincia de Jaén, para el municipio de Andújar, el art. 112 del Reglamento de Organización, Funcionamiento y Régimen Interno del Cuerpo de la Policía Local de Andújar ${ }^{22}$, establece la edad en similares parámetros a la Ley Andaluza, y también el art. 8 del Reglamento de Segunda Actividad de la Policía Local de $\mathrm{Martos}^{23}$, aunque sin previsiones para la escala técnica.

Las condiciones del traspaso en estos cuerpos varían en relación a los puestos de destino. El art. 34.4 de la Ley Murciana prevé, como norma, el desarrollo de la segunda actividad en el mismo cuerpo de pertenencia, desempeñando otras funciones, de acuerdo con su categoría, y sólo en caso de imposibilidad objetiva, por falta de puestos o por motivos de incapacidad, se pasará a prestar servicios complementarios adecuados a la categoría de pertenencia en otros puestos de trabajo de la misma corporación local, premisa más generalista en el caso andaluz, pues el art. 30 de la Ley Andaluza mantiene, igualmente, la preferencia de actividad dentro del área de seguridad, pero en caso de imposibilidad, el pase se producirá a otros servicios municipales, lo que levanta dudas acerca de la naturaleza de los mismos. Sobre el régimen retributivo, en ambos textos se establecen previsiones de salvaguarda frente a disminuciones de las retribuciones, salvo las que se deriven del puesto de trabajo o destino específico que se viniera desempeñando, según los acuerdos de condiciones de trabajo.

\section{Perspectivas desde la protección social}

\subsection{El encuadramiento}

Dada la organización territorial del Estado español en distintas Administraciones Públicas, el art. 2 de la Ley Orgánica 2/1986, de 13 de marzo, de Fuerzas y Cuerpos de Seguridad (LOFCS), prevé que cada Administración territorial pueda disponer de un cuerpo de seguridad propio inserto en su organización. De este modo, cabe distinguir los siguientes supuestos:

- Las Fuerzas y Cuerpos de seguridad del Estado, dependientes de la Administración General del Estado: el Cuerpo Nacional de Policía y la Guardia Civil.

\footnotetext{
21 BORM núm. 19, de 24 enero 2014.

22 BOP Jaén núm. 57, de 21 de marzo de 2012.

23 BOP Jaén núm. 6,5 de 4 de abril de 2014.
} 
— Los cuerpos de policía dependientes de las comunidades autónomas ${ }^{24}:$ la Ertzaintza en el País Vasco, la Policía Foral en Navarra, los Mossoss d' Escuadra en Cataluña y la Policía Canaria en Canarias.

- Los cuerpos de policía de las corporaciones municipales dependientes de los ayuntamientos.

- Otros cuerpos con funciones policiales: el Servicio de Vigilancia Aduanera, la policía portuaria, y los Agentes Forestales.

Esta variedad en cuanto a la adscripción administrativa de cada cuerpo ha supuesto que, tradicionalmente, el encaje dentro del sistema de Seguridad Social supusiera una maraña normativa, pues la protección social del personal funcionario público podía venir dada, de un lado, por el art. 136 RGSS $\mathrm{y}$, de otro, por el Régimen de Clases Pasivas del Estado ${ }^{25}$, expresión peculiar, todo sea dicho, del régimen funcionarial español, que no cuenta con traducción exacta en otros ordenamientos jurídicos, y por el que se gestionan las prestaciones o los «haberes pasivos» frente a los riesgos de vejez, incapacidad y muerte y supervivencia, de acuerdo con el art. 1.1 del Real Decreto Legislativo 670/1987, de 30 de abril, por el que se aprueba el Texto Refundido de la Ley de Clases Pasivas del Estado, cuyas disposiciones son comunes a todo el $\mathrm{Mu}$ tualismo Administrativo.

En este sentido, los policías municipales vienen encuadrados dentro del RGSS desde 1993, tras la desaparición de la Mutualidad Nacional de Previsión de la Administración Local (MUNPAL), por lo que les son de aplicación las disposiciones que rigen para las personas trabajadoras dependientes. Nada se dice en LGSS, o en los reglamentos de desarrollo de las previsiones del art. 161 bis, ni tampoco en la LOFCS, sobre la situación de penosidad, toxicidad, o situación de segunda actividad del cuerpo.

En cuanto al Régimen de Clases Pasivas del Estado, por ser el punto que aquí interesa, desde la aprobación de la Constitución Española de 1978, se ha visto inducido a movimientos hacia la homogeneización respecto al Régimen General de Seguridad Social, sobre todo a efectos de revalorización de pensiones

\footnotetext{
24 Además las comunidades autónomas del Principado de Asturias, Andalucía, Aragón, Galicia, y Comunidad Valenciana disponen de unidades adscritas del Cuerpo Nacional de Policía.

25 Dentro de su ámbito se halla incluida la MUFACE, Mutualidad General de Funcionarios Civiles del Estado, para funcionariado civil del Estado, regulada por el RD Legislativo, 4/2000 y RD 375/2003; el ISFAS, Instituto Social de las Fuerzas Armadas, para el personal militar, regulado por el RD Legislativo 1/2000 y RD 1726/2007; y la MUGEJU, en relación al personal al servicio de la Administración de Justicia, regulada por el RD Legislativo 3/2000 y RD 1026/2011. A ellos habría que añadir, a efectos meramente ilustrativos, la MUNPAL, Mutualidad Nacional de Previsión de la Administración Local, regulada por la Ley 11/1960, de 12 mayo, hasta su desaparición por el RD 480/1993, de 2 abril, que ordenó su integración el Régimen General de Seguridad Social. Sobre la materia puede verse, Rodríguez (2008: 154-169).
} 
y de racionalización del gasto (Calvo, 1988: 127). Esta imparable tendencia hacia la armonización parece atender a dos razones:

El primer motivo, de carácter jurídico, responde al enorme contraste entre la dualidad de cobertura y la evolución integradora del Sistema de Seguridad Social, abogándose ya entonces ampliamente por su superación, y sustitución por fórmulas más en consonancia con las tendencias actuales (De la Villa, 1971: 19).

El segundo motivo, de carácter economicista, responde a la estabilidad económica que supone para el Sistema de la Seguridad Social el aumento del número de cotizantes. Estas previsiones quedarían legisladas, entre otras, mediante la disposición final $4^{\text {a }}$ de la Ley 53/2002, de 30 diciembre, o la Ley 62/2003, de 30 de diciembre, en su disposición final $10^{\mathrm{a}}$, o incluso la disposición adicional $22^{\text {a }}$ de la Ley $2 / 2008$, de 23 de diciembre, que finalmente mandataba al Gobierno a emprender la senda definitiva de armonización.

Finalmente, el encargo fue cumplido mediante el art. 20 del Real DecretoLey 13/2010, de 3 de diciembre, de actuaciones en el ámbito fiscal, laboral y liberalizadoras para fomentar la inversión y la creación de empleo, ha sido el responsable de que el personal funcionario que ingrese en cualquier Administración Pública espańola a partir del 1 de enero de 2011 quede encuadrado dentro del RGSS a efectos de Clases Pasivas ${ }^{26}$, y en consecuencia, las pensiones de jubilación o retiro, incapacidad, de muerte y supervivencia, de este personal de nuevo ingreso será reconocidas por el Instituto Nacional de la Seguridad Social.

La integración en el Régimen General del nuevo funcionariado ha debido respetar las especificidades de cada uno de los colectivos relativas a la edad de jubilación forzosa, entre ellas, las que afectan al personal militar de carácter no permanente en cuanto a las contingencias no contempladas en la acción protectora del Régimen General, así como, para el personal de las Fuerzas Armadas y Fuerzas y Cuerpos de Seguridad del Estado, el régimen de las pensiones extraordinarias previsto en la normativa de Clases Pasivas.

En concreto, los sujetos concernidos y comprendidos en el clausurado Régimen de Clases Pasivas, según establece el art. 2.1 del RD Legislativo 670/198727:

- El personal funcionario de carrera de carácter civil de la Administración del Estado, es decir, los agentes del Cuerpo Nacional de Policía (art. 76.1 LO 9/2015).

26 Se salvaguarda, cuando así proceda, de acuerdo con su normativa, el Mutualismo Administrativo.

${ }^{27}$ Fernández (2009: 174) critica el carácter inacabado, al deber ser completado en atención a los reglamentos del mutualismo administrativo, con la reserva de Ley del art. 2.2 RD Leg 670/1987, para cualquier ampliación o restricción del ámbito personal de las Clases Pasivas. 
- El personal funcionario de carrera de la Administración de Justicia, es decir, el cuerpo de Policía Judicial, de acuerdo con el arts. 547 Ley Orgánica 6/1985, de 1 de julio, del Poder Judicial (en adelante, LOPJ) y 289 Ley de Enjuiciamiento Criminal.

— Los miembros de la Guardia Civil (art. 32 Ley Orgánica 11/2007, Ley Orgánica 11/2007, de 22 de octubre, reguladora de los derechos y deberes de los miembros de la Guardia Civil).

Igualmente, quedan comprendidos en el Régimen General de la Seguridad Social, según establece el art. 136 LGSS, los siguientes colectivos:

—Policías Nacionales, en virtud del RD Ley 13/2013, y art. 76.2 LO $9 / 2015$.

— Policías y bomberos de las comunidades autónomas: art. 136.2.l) LGSS.

- Policías municipales, bomberos municipales y agentes locales de medio ambiente: art. 1.1 RD 480/1993.

- Personal funcionario del Estado transferido a las comunidades autónomas que hayan ingresado o ingresen voluntariamente en cuerpos los escalas propios de la Administración de destino, cualquiera que sea el sistema de acceso: art. 136.2.l) LGSS.

- Personal funcionario interino de la Administración de Justicia, conforme al art. 472.2 LOPJ.

Por último, reseñar que el art. 95 quater, sobre disposiciones transitorias para la aplicación del Reglamento (CE) n. 1606/98, ha permitido que, desde el 25 de octubre de 1998, el régimen español del funcionariado público, civil y militar, esté incluido en el ámbito de aplicación de los Reglamentos Comunitarios de coordinación de Seguridad Social ${ }^{28}$, de modo que los períodos acreditados en otros Estados de la Unión Europea o del Espacio Económico Europeo sean considerados para el reconocimiento del derecho a pensión y para el cálculo de las pensiones del Régimen de Clases Pasivas.

28 Reglamento (CE) núm. 1606/1998 del Consejo, por el que se amplía el campo de aplicación de los Reglamentos (CEE) núm. 1408/71 y 574/72 del Consejo, a los regímenes especiales de funcionarios y normas de aplicación, ambos reemplazados por los Reglamento (CE) núm. 883/2004 sobre coordinación de seguridad social y Reglamento (CE) núm. 987/2009, sobre normas de aplicación del Reglamento 883/04. Téngase en cuenta, también, en cuanto pudiese resultar de aplicación la normativa nacional sobre convenios especiales para Personal de Organizaciones Internacionales y de la Unión Europea, el Real Decreto 2072/1999, de 30 de noviembre, sobre transferencias recíprocas de derechos entre el sistema de previsión social del personal de las Comunidades Europeas y los regímenes públicos de previsión social españoles. 


\subsection{El pase de la situación de segunda actividad a la jubilación mediante el anticipo de la edad ordinaria de retiro}

De acuerdo con el artículo 148.1.22 CE y el artículo 37 de la Ley Orgánica 2/1986, de 13 de marzo, de Fuerzas y Cuerpos de Seguridad, se autoriza a las comunidades autónomas en cuyos Estatutos esté previsto, la creación de Cuerpos de Policía propios para el ejercicio de las funciones de vigilancia y protección constitucionales, cuyo régimen estatutario, de conformidad con el art. 149.1.18 CE y art. 40 LOFCS, lo componen los principios generales del Título I de dicha Ley, las disposiciones al efecto de los Estatutos de Autonomía y la legislación específica de cada Comunidad Autónoma.

Respecto a la edad de jubilación de estos cuerpos, la Ley 24/2001, de Acompañamiento de los Presupuestos Generales del Estado para el año 2002, introdujo en su Disposición Adicional 32a una interpelación al Gobierno a:

analizar la situación de los funcionarios de las policías autonómicas en el nuevo marco de la jubilación gradual y flexible en función de la edad de jubilación en comparación con el resto de los Cuerpos y Fuerzas de Seguridad del Estado.

Sin embargo, esta Disposición Adicional no llegó a ser ejecutada. Y así se hizo constar en una resolución aprobada por el Congreso de los Diputados el 6 de junio de 2006, donde se instaba nuevamente al Gobierno a que en el marco de las previsiones contenidas en el apartado 2 del artículo 161 de la Ley General de la Seguridad Social (o incluso de otras fórmulas alternativas) se acometieran

las reformas que permitan, cumpliendo los principios y objetivos recogidos en el "Acuerdo sobre Seguridad Social», alcanzado en el marco del Diálogo Social, la reducción de la edad de jubilación de los funcionarios de las policías autonómicas integrales.

La referencia al Diálogo Social no era gratuita; el Acuerdo sobre Seguridad Social de 13 de julio de 2006 impulsó la reforma de Seguridad Social de 2007, mediante la Ley 40/2007, de 4 de diciembre, de medidas en materia de Seguridad Social, cuyo artículo 3.3 incorporó un nuevo artículo, el 161 bis, a la Ley General de la Seguridad Social, relativo a la jubilación anticipada en supuestos de trabajo extenuante, posibilitando el reconocimiento de la rebaja en la edad ordinaria de jubilación vía Real Decreto, a propuesta del Ministro de Trabajo y Asuntos Sociales, en aquellos grupos o actividades profesionales cuyos trabajos fueran de naturaleza excepcionalmente penosa, tóxica, peligrosa o insalubre y acusaran elevados índices de morbilidad o mortalidad.

A pesar de la habilitación legal antedicha, y de los numerosos intentos, la edad mínima no fue rebajada para las policías autonómicas, a excepción de la Policía Autonómica Vasca, la Ertzaintza, que poco tiempo después consiguió el 
reconocimiento de la jubilación anticipada a los 60 años $^{29}$. Las previsiones para la Ertzaintza fueron recogidas en la Disposición Final Tercera, regla trece, de la Ley 26/2009, de 23 diciembre, de Presupuestos Generales del Estado para el año 2010, por la que se establecía la Disposición Adicional Cuadragésima séptima LGSS, bajo la rúbrica "coeficientes reductores de la edad de jubilación de los miembros del Cuerpo de la Ertzaintza».

De modo que los restantes cuerpos autonómicos, los Mossos d'Esquadra ${ }^{30}$ y la Policía Foral de Navarra, se vieron indudablemente agraviados respecto al cuerpo policial de la Ertzaintza ${ }^{31}$. A ellos, habría que sumar en la actualidad la

29 ALDIZKARI OFIZIALA-BOLETIN OFICIAL núm. 56, de 2 febrero 2006, pág. 7661: Enmienda relativa a la regulación de la edad de pase a la segunda actividad en la Ertzaintza (núm. Expediente 08/11/02/01/0210), disponible en línea (22.IV.2016) www.legebiltzarra.eus/pdfdocs/ publi/1/08/000052.pdf: "El Parlamento vasco insta al Gobierno vasco a negociar durante la presente legislatura con el Gobierno del Estado el sistema por el que se aplique a la Ertzaintza el régimen de jubilación voluntaria anticipada existente en los Cuerpos y Fuerzas de Seguridad del Estado y presentar un proyecto de ley que desarrolle de manera inmediata el artículo 85 de la Ley 4/1992, de 17 de julio, de Policia del Pais Vasco, estableciendo posteriormente la edad de pase a la segunda actividad». El debate y resolución definitiva en BILKURIA EGUNKARIA-DIARIO DE SESIONES, núm. 43, de 3 noviembre 2006, págs. 36-40, disponible en línea (22.IV.2016) www.legebiltzarra.eus/pdfdocs/ publi/2/08/000043.pdf. No obstante, la medida fue rechazada por el Congreso en 2007.

30 Sobre la materia, el Parlament Catalán ha aprobado las siguientes Resoluciones:

— Resolució 442/VIII del Parlament de Catalunya, sobre l'equiparació de l'edat de jubilació dels membres de la Policía de la Generalitat-Mossos d'Esquadra amb els de la Policía Foral de Navarra i de l'Ertzaintza: «Reclamar al Govern de l'Estat l'elaboració de l'estudi sobre la possibilitat de reducció de l'edat de jubilació dels membres de les policies integrals a les quals fa referència l'apartat 1, donant compliment a la Proposició no de llei 162/000333, del 24 de març de 2009, sobre la reducció de l'edat de jubilació dels membres de la Policía de la Generalitat-Mossos d'Esquadra (PG-ME), aprovada pel Congrés dels Diputats", en línea (22.IV.2016) www. parlament.cat/getdocie/8008380.

— Resolució 323/X, apartado 1, punto XXVI: «El Parlament de Catalunya insta el Govern de l'Estat a estudiar la viabilitat de l'anticipació de l'edat de jubilació dels membres del Cos de Mossos d'Esquadra, en la mateixa linia que els altres cossos i forces de seguretat de l'Estat com Guàrdia Civil, el Cos Nacional de Policía i l'Ertzaintza», en línea (22.IV.2016) www.parlament.cat/ document/intrade/16684.

31 A nivel estatal, son también numerosas las actuaciones parlamentarias en búsqueda de la paridad entre cuerpos:

En 2007: Comparecencias para el estudio del régimen de la Seguridad Social de las policías autonómicas. Diario de Sesiones del Congreso de los Diputados, Comisión no permanente de seguimiento y evaluación de los acuerdos del Pacto de Toledo, en línea (22.IV.2016) www.congreso.es/ public_oficiales/L8/CONG/DS/CO/CO_970.PDF .

En 2008: Diario de Sesiones del Congreso de los Diputados, Comisión Interior, núm. 175, de 10 de diciembre de 2008, págs. 2-6; en línea (22.IV.2016) www.congreso.es/public_oficiales/L9/ CONG/DS/CO/CO_175.PDF

- Proposición no de Ley sobre la equiparación de la edad de jubilación entre los Mossos d'Esquadra-Policía de la Generalitat de Cataluña y las demás Policías Autonómicas. Presentada por el Grupo Parlamentario Catalán (Convergéncia y Unió).(Número de expediente $161 / 000553)$ 
policía autonómica de Canarias, denominada Policía Canaria, si bien no entró a formar parte del requerimiento inicial por ser instituida con posterioridad a dichas fechas.

La nueva minoración prevista para la policía autónoma vasca reduce la edad ordinaria exigida para el acceso a la pensión de jubilación en un período equivalente al que resulte de aplicar el coeficiente reductor del 20 por 100 a los años

— Proposición no de Ley sobre la reducción de la edad de jubilación de los miembros de la Policía de la Generalitat Mossos d'Esquadra (PG-ME). Presentada por el Grupo de Esquerra Republicana-Izquierda Unida-Iniciativa per Catalunya Verds (Número de expediente $161 / 000600)$

En 2009: BOCG. Congreso de los Diputados, núm.151, 20 de febrero de 2009, págs. 10-12, en línea, www.congreso.es/public_oficiales/L9/CONG/BOCG/D/D_151.PDF\#page=10

— Proposición no de Ley para la equiparación de la edad de jubilación entre los «Mossos d'Esquadra-Policía de la Generalitat de Cataluña» y las demás Policías Autonómicas. Presentada por el Grupo Parlamentario Catalán (Convergencia i Unió). Número de expediente 162/000323, en línea (22.IV.2016).

En 2010: Diario de Sesiones del Congreso de los Diputados, núm. 527, de 27 abril de 2010, págs. 15-21, en línea (22.IV.2016) www.congreso.es/public_oficiales/L9/CONG/DS/CO/CO_527. PDF

- Proposición no de Ley sobre la equiparación de la edad de jubilación de los "Mossos d'Esquadra», policía de la Generalitat de Catalunya y las demás policías autonómicas. Presentada por el Grupo Parlamentario Catalán (Convergencia i Unió). Número de expediente $161 / 001577$.

- Proposición no de Ley sobre la equiparación de la edad de jubilación de los diferentes cuerpos de Policía integral existentes en el Estado. Presentada por el Grupo Parlamentario de Esquerra Republicana-Izquierda Unida-Iniciativa per Catalunya Verds. Número de expediente $161 / 000592$.

- Proposición no de Ley sobre la equiparación de la edad de jubilación de los Mossos d'Esquadra a la de los miembros de la Ertzaintza y de las Fuerzas y Cuerpos de Seguridad del Estado. Presentada por el Grupo Parlamentario Esquerra Republicana-Izquierda Unida-Iniciativa per Catalunya Verds. Número de expediente 161/001433.

—Enmienda núm. 11 del Grupo Parlamentario Catalán (Convergència i Unió) al Proyecto de Ley sobre simplificación del intercambio de información e inteligencia entre los servicios de seguridad de los Estados miembros de la Unión Europea. BOCG. Congreso de los Diputados, serie A, núm. 48-8, de 24 de febrero de 2010, pág. 5, en línea (22.IV.2016) www. congreso.es/public_oficiales/L9/CONG/BOCG/A/A_048-08.PDF

En 2011: BOCG. Congreso de los Diputados Núm. D-625 de 12/09/2011 Pág.: 8. Puede verse en www.congreso.es/public_oficiales/L10/CONG/BOCG/B/BOCG-10-B-191-1.PDF

- Proposición no de Ley sobre regulación e implantación de coeficientes reductores en la edad de jubilación de los miembros de los Cuerpos de Policías Autonómicos y Locales. Grupo Parlamentario de Esquerra Republicana-Izquierda Unida-Iniciativa per Catalunya Verds (Número Expediente 162/000900), en línea (22.IV.2016), www.congreso.es/public_oficiales/L9/ CONG/BOCG/D/D_625.PDF\#page $=8$

En 2014: BOCG. Congreso de los Diputados Núm. B 191-1, de 5 de septiembre 2014.

—Proposición de Ley sobre jubilación anticipada. Presentada por el Grupo Parlamentario de IU, ICV-EUiA, CHA: Izquierda Plural (Número de Expediente 122/000169). 
completos efectivamente trabajados como miembros del cuerpo de la Ertzaintza o como integrantes de los colectivos que quedaron incluidos en el mismo.

La mecánica es similar a la aplicable para el cuerpo de bomberos. Se establece una edad mínima de jubilación de 60 ańos o 59 cuando se acrediten 35 o más años de cotización efectiva; además, se requerirá que la persona trabajadora se encuentre en alta al momento del hecho causante de la pensión de jubilación, por lo que el tiempo minorado se considerará como tiempo en alta, y computará como cotizado a efectos determinar el porcentaje aplicable a la correspondiente base para el cálculo del importe de la pensión de jubilación.

Se prevé la aplicación de un tipo de cotización adicional sobre la base de cotización por contingencias comunes, tanto para la empresa ${ }^{32}$ como para la persona trabajadora ${ }^{33}$, como consecuencia de la pérdida de cotizaciones por el adelanto de la edad de jubilación y del incremento en las prestaciones por los años en que se anticipa la jubilación, cuantía que es equiparable a la que la Administración del Estado abona por jubilación anticipada a los miembros de los Cuerpos y Fuerzas de Seguridad del Estado en el Régimen de Clases Pasivas. En la práctica, dada la lógica del sistema de reparto, la cotización por esos cinco años será mayor para el personal de acceso más reciente al cuerpo

Por tanto, hasta 2010, Mossos d'Esquadra, Ertzainas y Policías Forales de Navarra, sujetos al Régimen General de la Seguridad Social, debían esperar a la edad ordinaria para poder percibir el 100 por 100 de la pensión; de lo contrario se les aplicaba el pertinente coeficiente corrector por anticipo voluntario, entonces del 8 por 100 , por cada año de anticipo.

En atención al encuadramiento de los tres cuerpos en el Régimen General de la Seguridad Social, es coherente plantearse que todos ellos deban gozar de los mismos derechos, como se desprende del artículo 14 de la Carta Magna, prohibición de discriminación que reiterada jurisprudencia constitucional ha señalado que no se identifica con cualquier diferencia de trato, sino solamente con aquellas que carezcan de una justificación objetiva y razonable desde las premisas sentadas por la Constitución ¿AAcaso los índices de morbilidad o mortalidad varían tan drásticamente entre estos colectivos?

32 Tipo de cotización adicional a cargo de la empresa por jubilación anticipada de Bomberos y Ertzaintza respectivamente: en 2010 arts. 30.6 y 30.7 OM TIN/25/2010 (5.4\% y 3.34\%); en 2011 arts. 30.6 y 30.7 OM TIN/41/2011 (5.67\% y 4.17\%); en 2012 arts. 30.6 y 30.7 ESS/184/2012 (5.92\% y 5.42\%); en 2013 arts. 30.3 y 30.4 OM ESS/56/2013 (6.09\% y 5.67\%); en 2014 arts.30.3 y 30.4 OM ESS/106/2014 (6.67\% y 5.92\%); en 2015 arts.30.3 y 30.4 OM ESS/86/2015 (7.17\% y $6.09 \%$ ); en 2016 arts.30.3 y 30.4 OM ESS/70/2016 (7.67\% y $6.67 \%$ )

33 Tipo de cotización adicional a cargo de la persona trabajadora por jubilación anticipada de Bomberos y Ertzaintza respectivamente: en 2010 (1.08\% y 0.67\%); en 2011 (1.13\% y 0.83\%); en 2012 (1.18\% y $1.08 \%)$; en 2013 (1.21\% y $1.13 \%)$; en 2014 (1.33\% y $1.18 \%)$; en 2015 ( $1.43 \%$ y $1.21 \%$ ); en 2016 (1.53\% y $1.33 \%)$. 
A tenor de esta situación, también se han pronunciado los cuerpos de policías locales. El anticipo de la edad de jubilación es una constante reivindicación de la acción sindical de este colectivo ${ }^{34}$. Mediante diferentes acciones de distintas instancias sindicales se está materializando la unidad entre cuerpos y sus representantes; así, la Confederación de Seguridad Local (CSL), la Coordinadora de Policía (COP) y la Plataforma Social de Policías Locales (PSPL), se han movilizado en pro de este objetivo, manteniendo encuentros con la Secretaría de Estado de Seguridad Social, con los distintos grupos parlamentarios y, unidas a las tres organizaciones sindicales mayoritarias, han desarrollado un plan de reivindicaciones que se justifican en la garantía del servicio público destinado a la ciudadanía.

Las distintas acciones sindicales confluyeron en la formalización del Acuerdo de defensa del anticipo de la edad de jubilación para los funcionarios de policía local y autonómico, con fecha de 19 julio 2010, que ha supuesto la adhesión de los sindicatos de personal funcionario de la policía local y autonómica de todo el país, junto a la que ya mantenían CSI-F, CCOO y UGT.

Desde entonces, las movilizaciones de este colectivo se han ido viendo atendidas por distintos organismos públicos, políticos y sociales ${ }^{35}$, que respaldan la inclusión de los policías locales entre las categorías de especial penosidad, toxicidad, peligrosidad o insalubridad, y elevados índices de morbilidad o mortalidad, con el objetivo de alcanzar una equiparación respecto al colectivo de bomberos y de la Ertzaintza. En este sentido, conviene no olvidar que la Disposición Adicional Sexta de la Ley 7/2007, del Estatuto Básico del Empleado Público (EBEP), mandataba al Gobierno a evitar "la discriminación entre colectivos con características similares», promoviendo para ello "la conveniencia de ampliar la posibilidad de acceder a la jubilación anticipada de determinados colectivos", y en similares términos la reciente Disposición Adicional Quinta del Real Decreto Legislativo 5/2015, de 30 de octubre, por el que se aprueba el texto refundido de la Ley del Estatuto Básico del Empleado Público.

Pero la entrada de dicha cuestión en la agenda política no ha sido un camino fácil. Ya en la Comisión de Interior de 15 Diciembre 2009, en la tramitación del Proyecto de Ley Orgánica del Régimen Disciplinario de la Policía, se aprovechó la ocasión para dejar constancia de estas peticiones por parte de repre-

34 Desde 2003 varios sindicatos de Policía Local se coordinaron, creando la PSPL, para poner fin al agravio comparativo existente en materia de jubilación respecto a otros Cuerpos de Seguridad. Ha habido concentraciones y protestas en Madrid, el 22 Noviembre 2007 [organizada por la Coordinadora de Policías (COP)]; el 17 de Junio de 2009 y 28 de Junio de 2011 (COP y CLS); y la manifestación de 23 febrero 2010, como protesta por el anuncio del Gobierno del incremento de la edad de jubilación de los 65 a los 67 años.

35 Aprobadas mociones en plenos que respaldan la jubilación anticipada en ayuntamientos de grandes núcleos de población. 
sentantes sindicales del sindicato profesional de policías municipales (SSPME) y de representantes UGT de la administración autonómica y local ${ }^{36}$.

A lo anterior siguieron intentos frustrados, a través de enmiendas ${ }^{37}$, o proposiciones no de Ley, como las presentadas a la Comisión de Empleo y Seguridad Social del Congreso de los Diputados, el 27 febrero 2012, por el Grupo Parlamentario Izquierda plural ${ }^{38}$, o el 14 de julio de 2014, por el Grupo Parlamentario de Unión Progreso y Democracia ${ }^{39}$. No obstante, durante el debate de esta última se convino en proseguir el procedimiento marcado por la legislación de la Seguridad Social a través de la Secretaría de Estado de la Seguridad Social.

Lo cierto es que para entonces ya se había abierto otra vía a través de la participación de la Federación Española de Municipios y Provincias (FEMP), cuya estructura está permitiendo recabar la información requerida para el reconocimiento del derecho futuro. En el escrito fechado el 16 de octubre de 2013 se procedió, en nombre de la Plataforma Sindical por el Adelanto de la Edad de Jubilación de los Policías Locales y Autonómicos, al registro de solicitud de reunión al presidente de la FEMP. En base al acuerdo alcanzado, la FEMP ha comenzado la recopilación documental para la elaboración de los estudios requeridos por el procedimiento de reconocimiento del RD 1698/2011. En la Circular n. $16 / 2015$, de 24 febrero $2015^{40}$, la FEMP

agradece la colaboración de las Entidades Locales con Policía Local que han atendido la petición de suministro de datos para la elaboración del estudio sobre la posibilidad de anticipar la edad de jubilación de los Policías Locales, formulada a la Federación por la Secretaría de Estado de la Seguridad Social. Asimismo, aprovecha para recor-

36 Diario Sesiones Congreso Diputados, Comisión interior, Sesión núm. 24, 15 diciembre 2009, Núm. 447, pág. 7, en línea (22.IV.2016), www.congreso.es/public_oficiales/L9/CONG/DS/ CO/CO_447.PDF.

37 Véase, Enmienda núm. 1.465 presentada por Grupo Parlamentario de Esquerra RepublicanaIzquierda Unida-Iniciativa per Catalunya Verds, a la Disposición Final tercera de la Ley de Presupuesto del Estado 2011.

38 Proposición no de Ley presentada por el Grupo Parlamentario de IU, ICV-EUIA, CHA: La izquierda Plural, sobre regulación e implantación de coeficientes reductores en la edad de jubilación de los miembros de los Cuerpos de Policías Autonómicos y Locales (Número Expediente 161/000244), BOCG. Congreso de los Diputados, Serie D, Núm. 43, 27 de febrero de 2012, pág. 23, en línea (22.IV.2016), www.congreso.es/public_oficiales/L10/CONG/BOCG/D/D_043. PDF

39 Proposición no de Ley presentada por el Grupo Parlamentario Unión Progreso y Democracia, sobre la implantación de coeficientes reductores en la edad de jubilación de los policías locales (Núm. Exp. 161/002931/0000), BOCG. Congreso de los Diputados, Serie D, Núm. 503, 28 julio de 2014, pág. 7, en línea (22.IV.2016), www.congreso.es/public_oficiales/L10/CONG/BOCG/D/ BOCG-10-D-503.PDF

40 Circular Federación Española de Municipios y Provincias, núm. 16 de 24 de febrero de 2015; puede verse en línea (22.IV.2016) www.femp.es/files/3580-1026-fichero/Circular\%2016-2015\%20 Tasa\%20de\%20reposicionúm.pdf 
dar a todas aquellas Entidades Locales que, teniendo Policía Local, no hayan facilitado dicha información, que se encuentran todavía en plazo para hacerlo.

No obstante, no fue el primer contacto entre las partes ${ }^{41}$. En cualquier caso, hasta el momento no hay suficientes estudios que avalen la conveniencia reducir la edad de jubilación a policías locales, incluso un vistazo al derecho comparado sobre estos informes científicos arroja situaciones paradójicas como el detectado en el cuerpo de bomberos de Hamburgo y una menor tasa de mortalidad en comparación con la población general (Barceló, 2016: 277).

\section{Limitación en el acceso a los cuerpos funcionarios provistos de segunda actividad}

Por último, a sensu contrario, otro de los aspectos a tener en consideración respecto a la totalidad de cuerpos de seguridad públicos, es la limitación de edad en el acceso al cuerpo. Del mismo modo que los requerimiento físicos son una condición imperativa de acceso y permanencia en aquel, el deterioro derivado del cumplimiento de una determinada edad de los aspirantes es otro proceso paralelo, que repercutirá en el tiempo efectivo de carrera de servicio y, por tanto, de cotización de los futuros miembros. La cuestión objeto de debate ha sido la de si es o no legítimo establecer tales limites.

La cuestión ha sido resuelta por el Tribunal Supremo en las SSTS 2185/2011 y 2187/2011, de 21 marzo, anulando el límite de edad, al no considerarlo un requisito "esencial y determinante para desempeñar los cometidos exigidos a un policía nacionali. Estas sentencias están siendo trasladadas de manera distinta a las respectivas normativas de personal del Cuerpo de la Policía Nacional y de la Guardia Civil.

Para la Policía Nacional supuso la eliminación de cualquier mención al límite máximo de edad, en la nueva Ley de Personal de Policía Nacional, tanto para la Escala Ejecutiva como para la Escala Básica, en base a los principios de igualdad y no discriminación en el acceso al empleo público defendidos en la sentencia.

Por su parte, respecto de la Guardia Civil, la Sala Tercera del Tribunal Supremo, en la sentencia núm. 168/2016, de 1 febrero 2016, declara nulo el artículo 18.3.b), sobre el límite máximo de edad de participación en las convo-

41 También, vía Defensor del Pueblo, el 19 abril de 2012, la Federación de Servicios Públicos de UGT y el SIPLA presentaron una queja por vulneración del principio de igualdad en relación al anticipo de la edad de jubilación de la policía autonómica y local, por el desigual cese de actividad profesional policial que, en razón de edad o de patologías profesionales, y en base a estudios médicos y la propia experiencia profesional del deterioro de las condiciones físicas, y su repercusión en la prestación del servicio. 
catorias de empleo, del Real Decreto 597/2002, de 28 de junio, por el que se aprueba el Reglamento general de ingreso en los centros docentes de formación del Cuerpo de la Guardia Civil, por considerarlo un requisito discriminatorio. No obstante, las Escalas Facultativa Superior y Facultativa Técnica (creadas con la Ley 42/99) han sido suprimidas por la nueva Ley 29/2014, de 28 de noviembre, de modo que la virtualidad práctica de la sentencia es nula. De hecho, la Ley 29/2014 prevé las edades máximas para poder participar en los procesos selectivos de los distintos sistemas de acceso a los centros de formación de la Guardia Civil, tanto en el acceso directo a la escala de cabos y guardias (40 años) como en la promoción profesional (50 años), según defiende la exposición de motivos de la norma ${ }^{42}$.

La comparativa con la Policía Nacional es evidente, de modo que la atención se sitúa, por lo pronto, en determinar si se respetará el criterio del Tribunal Supremo o habrá que esperar a una sentencia firme específica. Lo cierto es que los principios enunciados por el Tribunal Supremo podrían ser trasladables a cualquier cuerpo policial y, por tanto, deberían tenerse en cuenta para evitar futuras sentencias desfavorables a la limitación de edad, salvo que, como se ha aprendido de la experiencia, la limitación esté justificada y venga recogida en norma con rango de ley. Este es, en definitiva, otro elemento más a tener en consideración en el camino hacia la homogeneización de las distintas edades policiales.

Por último, respecto a los cuerpos de policía local, nuevamente el Tribunal Supremo, en su sentencia 575/2014, de 3 de febrero de 2014, ha tenido ocasión de corroborar sus sentencias anteriores y confirmar la nulidad de tal medida para las personas aspirantes a plazas de policía local del Ayuntamiento de Sevilla, desde una doble perspectiva: una formal sobre el principio de legalidad y otra sustantiva, sobre la razonabilidad, objetividad y proporcionalidad de la medida (Ortega, 2010: 1767). Al respecto, el Alto Tribunal ha confirmado la sentencia de origen, sentencia del Juzgado de lo Contencioso-Administrativo núm. 9 de Sevilla de 28 de julio de 2009, señalando que

tratándose del ingreso en Cuerpos de Policía Local, será la Ley la que debe imponer la edad máxima cuando se quiera una distinta a la de jubilación forzosa y la que se

42 Respecto al acceso directo, los motivos de edad corresponden, a la adquisición primero y mantenimiento después de las destrezas psicofísicas necesarias para desempeñar cometidos en áreas concretas de actividades de aquellas especialidades, muchas de las cuales requieren medios y procedimientos en los que aquellas condiciones, tanto en su inicio como mantenidas en el tiempo, son no solo fundamentales, sino que garantizan la seguridad e integridad de los propios agentes.

Respecto a la promoción profesional, ha de ponerse en relación la formación recibida en el proceso de promoción con el tiempo disponible para aplicar los conocimientos adquiridos, y que la participación en dichos procesos de promoción se haga con una edad que permita alcanzar en la carrera profesional ciertos empleos, y que la experiencia profesional alcanzada permita nutrir las necesidades que, en cada uno de ellos, tenga la Guardia Civil. 
elija ha de estar justificada en función de los cometidos asignados a esos cuerpos; se sigue, pues, el criterio de la sentencia de origen, que se opone a la discriminación injustificada para acceder a la función pública.

Estas nuevas líneas jurisprudenciales deben ponerse en relación con la jurisprudencia del Tribunal de Justicia de la Unión Europea que hasta en 3 ocasiones ha tenido oportunidad de pronunciarse al respecto. La STJUE de 13 de noviembre de 2014 (Asunto C-416/2013, Caso Vital Pérez) consideró discriminatorio y contrario a la Directiva 2000/78/CE el límite de edad en el acceso a la policía local: la edad máxima de 30 años para acceder a las pruebas selectivas de los agentes de policía local no puede justificarse apelando a las exigencias físicas de la actividad ni tampoco apelando a razones de política de empleo (Fernández, 2015:33), apartándose así del criterio de la STJUE de 12 de enero de 2010 (Asunto C-229/2008, Caso Wolf) donde se consideraba justificada la restricción al acceso al cuerpo de bomberos en razón de las extraordinarias exigencias físicas que reclama el ejercicio de las tareas de esta profesión, como así lo habían entendiendo también distintos Tribunales Superiores de Justicia en el Estado espanol ${ }^{43}$.

No obstante, la más reciente STJUE de 15 de noviembre de 2016 (Asunto C-258/2015, Caso Salaberría Sorondo) ha corroborado los razonamientos de 2010 que justificaban la discriminación por razón de edad controvertida, al entender que las funciones correspondientes a la Escala Básica de la Ertzaintza implican tareas particularmente exigentes desde un punto de vista físico, circunstancia que nuevamente no concurre con la misma intensidad en los cuerpos de policía local.

Se ha criticado que además, en la sentencia examinada el TJUE no aluda al instrumento jurídico necesario para prever por parte de los Estados miembros los límites de edad para el acceso a la función pública (como más arriba se apuntó hizo el Tribunal Supremo respecto a la policía local), es decir, el TJUE no cuestiona si el Decreto vasco que regula tal limitación ofrece la suficiente cobertura jurídica (Agoués, 2017).

Por el contrario, otro sector doctrinal, ha interpretado esta situación como un reconocimiento de las facultades de autoorganización de la Administración Vasca en la planificación de personal, porque en el establecimiento de una pirámide de edades satisfactoria, la condición física no puede resultar estática, únicamente durante las pruebas del proceso selectivo, sino dinámica, teniendo en

43 En relación al límite de acceso al cuerpo de bomberos véase las STSJ de Andalucía-Sevilla, de 27 de enero de 2009, STSJ de Extremadura de 30 de enero de 2009; SSTSJ de Cataluńa de 7 de abril de 2000, de 18 de noviembre de 2004, y de 31 de enero de 2006; STSJ de Castilla y León de 23 de febrero de 2007, todas ellas comentadas en Ortega (2010: 1767). 
consideración los años de servicio a prestar por el agente después de ser seleccionado (Fragoso, 2017).

\section{Comparativa a nivel estatal del régimen jurídico de segunda actividad y reserva}

El artículo $104 \mathrm{CE}$ establece que mediante ley orgánica se determinarán las funciones, principios básicos de actuación y estatutos de las Fuerzas y Cuerpos de Seguridad, siendo competencia exclusiva del Estado la materia de seguridad pública, y de Fuerzas Armadas y Defensa (artículo 149.1.29a y $4^{a} \mathrm{CE}$ ), incluida la determinación del régimen estatutario y de personal de la Guardia Civil, como integrante de las Fuerzas y Cuerpos de Seguridad del Estado.

En desarrollo de estas previsiones constitucionales se aprobó la primigenia Ley Orgánica 2/1986, de 13 de marzo, de Fuerzas y Cuerpos de Seguridad. Dicha norma contenía, en relación a la Guardia Civil, los rasgos básicos de su régimen estatutario, el cual pasaría a estar conformado por esta, junto a la normativa posterior de desarrollo de la misma, y la normativa del ordenamiento militar.

La Ley 17/1989, de 19 de julio, reguladora del Régimen del Personal Militar Profesional, junto a la Ley 28/1994, de 18 de octubre, de 18 de octubre, por la que se completa el régimen del personal del Cuerpo de la Guardia Civil, fueron los primeros textos encargados de articular dicho desarrollo legal. Ambas normas vendrían "casadas" y actualizadas mediante la Ley 42/1999, de 25 de noviembre, de Régimen del Personal del Cuerpo de la Guardia Civil, la primera ley propiamente estatutaria y específica para los miembros del Instituto armado militar, que ha permanecido en vigor durante casi una veintena de años.

En este periodo, dos fueron las previsiones relevantes que la han afectado y han abocado a la publicación de un nuevo texto legal: en primer lugar, la Disposición Final Séptima de la Ley 39/2007, de 19 de noviembre, de la carrera militar, que encomienda al Gobierno remitir a las Cortes General un proyecto de ley que actualice el régimen del personal del Cuerpo de la Guardia Civil, «teniendo en cuenta la naturaleza del cuerpo", con el objetivo de integrar escalas profesionales, a la vez que regular los sistemas de enseñanza y promoción profesional de sus miembros; $y$, en segundo lugar, la necesidad de completar el trabajo emprendido con la aprobación de Ley Orgánica 11/2007, de 22 de octubre, reguladora de los derechos y deberes de los miembros de la Guardia Civil, y la Ley Orgánica 12/2007, de 22 de octubre, del régimen disciplinario de la Guardia Civil, para adaptar las normas de aplicación general a la función pública recogidas por la Ley 7/2007, de 12 de abril, del Estatuto Básico del Empleado Público $\mathrm{y}$ adaptadas a sus peculiaridades. 
Como resultado de este proyecto se ha configurado, finalmente, un régimen personal pleno y propio, regulado en la reciente Ley 29/2014, de 28 de noviembre, de Régimen del Personal de Guardia Civil ${ }^{44}$.

El cese de servicios profesionales o "pase a retiro» dentro del cuerpo de la Guardia Civil por cumplimiento de edad, se establece al acaecimiento de los 65 años edad (art. 94.1 Ley 29/2014), bien desde la situación de servicio activo a petición propia de la persona interesada (por periodos prorrogables de un año, se podrá conceder la continuación en servicio activo hasta cumplir la edad de 60 ańos a los miembros de la categoría de suboficiales y de 65 para cabos y guardias), bien tras el paso por la "situación de reserva» (art. 93.1 Ley 29/2014), y en atención a los cupos previstos conjuntamente por los Ministerios de Defensa e Interior, y una carencia de 20 años de servicios desde la adquisición de la condición de guardia civil. Las edades de pase a reserva varían en función de la escala de pertenencia ${ }^{45}$.

El otro aspecto de relevancia en la situación de reserva son las retribuciones (art. 93.10 Ley 29/2014), las cuales vienen genéricamente referidas a la norma específica reguladora del sistema retributivo, con dos puntualizaciones; la primera, para el personal no destinado, cuyas retribuciones estarán, en todo caso, constituidas por las retribuciones básicas y un complemento de disponibilidad; la segunda, para las retribuciones de la categoría contenida en la letra a) del apartado primero, referida a la categoría de Oficiales Generales (Teniente General, General de División y General de Brigada), que conservarán las retribuciones del personal en activo hasta alcanzar la edad de 63 años.

En relación a la redenominada Policía Nacional, la mencionada Ley Orgánica 2/1986, de 13 de marzo, de Fuerzas y Cuerpos de Seguridad integró en un nuevo Cuerpo, el Cuerpo Nacional de Policía, el, entonces, Cuerpo Superior de Policía y el Cuerpo de Policía Nacional, y estableció en su artículo 16.3 la edad de 65 años como determinante de la jubilación forzosa. Antes de llegar a ella,

44 Se regula la nueva condición de "Guardia Civil en suspenso», para quienes se encuentren en situación de servicios especiales: los mismos no estarán sujetos al régimen general de derechos y deberes ni al régimen disciplinario de la Guardia Civil, ni al Código Penal Militar.

45 Edad del pase a reserva en el cuerpo de la Guardia Civil en relación a empleos y escalas. Ley 28/1994, art. 11: Oficiales generales (General de División 62 años y Generales de Brigada 60 años); Oficiales Superiores (Coronel, Teniente-Coronel, Comandante 58 años); Oficiales (Capitán, Teniente, Alférez 58 años); Suboficiales Superiores (Suboficial Mayor y Subteniente 58 años); Suboficiales (Brigada, Sargento $1 .^{\circ}$ y Sargento 56 ańos); Cabos y Guardias (Cabo 1. ${ }^{\circ}$ y Cabo G. Civil 56 años). Ley 29/2014, art. 93: Oficiales Generales (Teniente General, General de División, General de Brigada pasarán a reserva al cumplir cuatro ańos en el empleo de General de Brigada o siete entre los empleos de General de Brigada y General de División, o diez entre los anteriores y el de Teniente General); Oficiales (Coronel, Teniente-Coronel, Comandante, Capitán y Teniente 61años); Suboficiales (Suboficial Mayor, Subteniente, Brigada, Sargento 1. ${ }^{\circ}$ y Sargento 58); Categoría de Cabos y Guardias (Cabo Mayor, Cabo $1 .^{\circ}$ y Cabo G. Civil 58 años) 
el punto cuarto preveía la las edades y causas del pase a la llamada situación de «segunda actividad», vía reserva legal, en atención a las aptitudes físicas que demandase su función, así como de las remuneraciones y las obligaciones correspondientes a dicha situación, puesto que, en la situación preveía a su entrada en vigor, el Cuerpo Superior de Policía carecía de tales previsiones, mientras que para el Cuerpo de Policía Nacional ya había sido creada, por la Disposición Adicional 2a Ley 55/1978, de 4 de diciembre, desarrollada por el Real Decreto 230/1982, de 1 de febrero.

La Disposición Transitoria cuarta de la Ley Orgánica 2/1986, estableció que, hasta tanto sea desarrollada la situación de segunda actividad para el nuevo Cuerpo Nacional de Policía, los procedentes del Cuerpo de la Policía Nacional seguirían rigiéndose por la normativa que les venía siendo aplicada; y los procedentes del Cuerpo Superior de Policía pasarían a esta situación al cumplimiento de la edad de 62 años $^{46}$. Como paso indispensable, se produjo la integración previa definitiva en una misma escala, de las edades de pase a la situación de segunda actividad, lo que vino de la mano de la DA 20a de la Ley de Presupuestos Generales del Estado para 1989 (Ley 37/1988, de 28 de diciembre).

Finalmente, en cumplimiento de las previsiones del artículo 16.4 Ley Orgánica 2/1986, se publicó la Ley 26/1994, de 29 de septiembre, por la que se regula la situación de segunda actividad en el Cuerpo Nacional de Policía, definiendo la misma por su finalidad, la garantía de una adecuada aptitud psicofísica del personal funcionario del Cuerpo Nacional de Policía mientras permaneciesen en activo (a excepción de personal facultativo y técnico), y la eficacia del servicio. El hecho causante se entendía causado en base a tres supuestos: 1) el cumplimiento de las edades legalmente previstas (su evolución normativa se recopila en una tabla comparativa más adelante); 2) a petición de la persona interesada, tras veinticinco años efectivos en las situaciones de servicio activo ${ }^{47}$, condicionada a la aprobación de las plazas correspondientes por el Ministerio del Interior; 3) de oficio por la propia Administración, tras la constatación de insuficiencia en las aptitudes psicofísicas necesarias, en la persona de que se tratara, para el desempeño de la función policial. Esta inhabilitación podía ser de carácter temporal hasta el cese de dicha carencia, siempre y cuando no se hubiese alcanzado la edad prevista de pase a segunda actividad.

Tal y como declaraba su exposición de motivos, la norma se guiaba por los criterios de racionalidad y congruencia, de modo que las rúbricas dedicadas a

46 El RD 311/1988, de 30 de marzo, de Retribuciones del Personal de las Fuerzas y Cuerpos de Seguridad del Estado, en su disposición transitoria segunda, regula las retribuciones de quienes accedan a la situación de segunda actividad.

47 El art. 5 Ley 26/1994 es heredero del artículo 6 RD 230/1982, el cual exigía 25 años de servicios efectivos desde la toma de posesión del primer empleo de Oficial o Suboficial, o 30 años de servicios efectivos desde el ingreso en el Cuerpo de la Policía Nacional. 
remuneración procuran, en cierta medida, salvaguardar los derechos económicos de este personal. De este modo, se distinguía entre los supuestos con destino efectivo o aquellos sin destino.

En el primer caso, se percibía la totalidad de las retribuciones generales correspondientes a su categoría en activo, las de carácter personal que tuviese reconocidas en tal fecha o llegase a perfeccionar, además de las específicas inherentes al nuevo puesto de trabajo (y en aquellos casos que procediese, sería reconocido igualmente el complemento de productividad). De suponer esta cuantía una pérdida económica respecto a la situación previa, el art. 10 Ley 26/1994 garantizaba el derecho a un complemento transitorio en cuantía necesaria que permitiese alcanzar la remuneración inicial.

En el segundo supuesto, durante la permanencia en la situación de segunda actividad sin destino, a la totalidad de las retribuciones básicas por antigüedad y categoría, se le adicionaba un complemento de compensación equivalente al 80 por 100 de las retribuciones complementarias de carácter general de la referida categoría. En ambos supuestos, en caso de carecer del mínimo de ańos de servicios requerido, la retribución a percibir únicamente correspondería a las básicas, en función del tiempo efectivo de servicios prestados, según se estableciese reglamentariamente.

Esta normativa estuvo en vigor durante dos décadas ${ }^{48}$, hasta la aprobación definitiva de la nueva Ley Orgánica 9/2015, de 28 de julio, de Régimen de Personal de la Policía Nacional, lo referente a segunda actividad en el Proyecto de Ley no tuvo modificación alguna ${ }^{49}$.

La nueva norma contiene cuatro variaciones significativas. Las primeras, en relación al incremento de las edades en función de la escala profesional, cuyo incremento recoge la tabla siguiente, y respecto de cuya aplicación, la Disposición Transitoria $3^{a}$ ha establecido una serie de cautelas para garantizar las expectativas de derecho vigentes a la entrada en vigor de la norma ${ }^{50}$. Las segundas variaciones, en cuanto al régimen retributivo; a saber:

48 Proyecto de Ley Orgánica del Régimen de Personal de Policía Nacional, BOCG núm. 123, 5 de diciembre de 2014, en línea (22.IV.2016). www.congreso.es/public_oficiales/L10/CONG/ BOCG/A/BOCG-10-A-123-1.PDF .

49 Edad del pase a segunda actividad para el cuerpo de Policía Nacional. Ley Orgánica 2/1986 y Ley 37/1988: escala superior 58 años y Escala ejecutiva 56 ańos. Ley 26/1994: Escala superior 60 años, escala ejecutiva (se fracciona en tres escalas) escala ejecutiva 56 años; escala de Subinspección 55 años y escala básica 55 años. Ley orgánica 9/2015: escala superior 64 años (1. ${ }^{\circ}$ Comisario General, 2. ${ }^{\circ}$ Comisario Principal, 3. ${ }^{\circ}$ Comisario); escala ejecutiva 62 años (1..$^{\circ}$ inspector jefe y 2. ${ }^{\circ}$ inspector); escala de subinspección 60 años; escala básica 58 años (1. ${ }^{\circ}$ oficial y Policía).

50 Los/las Policías Nacionales que se hallasen en servicio activo a fecha 31 de diciembre de 2001, podrán optar, de forma expresa e individualizada, por pasar a segunda actividad en cualquier momento, a partir del cumplimiento de las edades correspondientes: Escala Superior: 60 ańos; Escala Ejecutiva: 56 años; Escala Subinspección: 55 años; Escala Básica: 55 años. Por su parte, respecto 
a) La retribución a percibir en situación de segunda actividad queda igualada, independientemente de la situación de destino efectivo, en la cantidad correspondiente a la suma de la retribución básica según antigüedad y categoría de pertenencia, y un complemento del 80 por 100 de las retribuciones complementarias de carácter general de la categoría correspondiente.

b) Se prevé un nuevo supuesto retributivo, cuando la segunda actividad viniese ocasionada por enfermedad o accidente profesional producidos en acto de servicio o como consecuencia del mismo, al que se atribuye el 100 por 100 de las retribuciones que se vinieran devengando en situación de servicio activo.

c) Las peculiaridades retributivas concretan el mínimo de años de servicios en 20 (art. 74 L.O 9/2015), cuando el pase a segunda actividad por petición propia continua en 25 años de servicio efectivo (art. 69 LO 9/2015).

Se ha de señalar que los artículos 4 y 5 RD-Ley 14/2011, de medidas complementarias en materia de políticas de empleo y de regulación del régimen de actividad de las Fuerzas y Cuerpos de Seguridad del Estado, modificó la permanencia en servicio en activo, para los miembros del Cuerpo de la Policía Nacional (entendiendo por servicio activo las definiciones de los art. 53 LO 9/2015 y art. 88 Ley 29/2014), así como para determinados miembros de la Guardia Civil (categorías de Cabos y Guardias), hasta el cumplimiento de la edad de 65 años, siempre y cuando se reúnan las condiciones adecuadas para el desempeño.

\section{Conclusiones}

La situación de segunda actividad es configurada en la mayoría de la normativa autonómica como situación administrativa especial, a pesar de que conceptualmente también cabe la posibilidad de definirla como una modalidad de servicio activo. Igualmente, supone una práctica generalizada regular la materia mediante previsiones por parte de leyes autonómicas de coordinación de cuerpos de policías locales, las cuales, como constata la doctrina jurisprudencial, no pueden prefigurar exhaustivamente el contenido de la actividad del ente coordinado, pues confrontaría con el principio de autonomía local. Como resultado, se produce el cambio a un puesto compatible con la nueva realidad psicofísica de la persona funcionaria dentro del mismo cuerpo, siempre que exista disponibilidad de plazas, o en su defecto, en otras del mismo Ayuntamiento. Algunas

de los/las Policías Nacionales que se hallasen en servicio activo a fecha de 20 de septiembre de 2011: Escala Superior: 62 años; Escala Ejecutiva: 58 años; Escala Subinspección: 58 años; Escala Básica: 58 años. 
Administraciones han unificado criterios en cuanto a los distintos cuerpos de seguridad en ellas presentes. La práctica cotidiana suele traducirse en el desempeño de puestos burocráticos en la propia plantilla de cuerpo o, en su defecto, en otros servicios manteniendo la situación de servicio activo.

A nivel estatal cabe resaltar la diferencia entre los institutos armados civil y militar, pues el primero presenta un régimen más beneficioso que el segundo. Dicho agravio se produce, de un lado, por la falta de previsión legal para el paso a la situación de reserva motivada en la insuficiencia de aptitudes psicofísicas, a diferencia de la segunda actividad de policías nacionales; y, de otro lado, por el régimen de incompatibilidades durante la situación de reserva, a diferencia de la posibilidad de los policías nacionales de desarrollar otras actividades profesionales privadas sin mediar un reconocimiento previo de compatibilidad. La comparativa entre las respectivas leyes de personal de ambos cuerpos es inevitable, máxime cuando a pesar del pequeńo lapso temporal existente entre ambas, su tramitación parlamentaria no fue, inexplicablemente, conjunta.

Por último, y a sensu contrario, otro de los aspectos a tener en consideración será la limitación de edad en el acceso al cuerpo. Del mismo modo que los requerimientos físicos son una condición imperativa de acceso y permanencia en aquel, el deterioro derivado del cumplimiento de una determinada edad de los aspirantes constituye otro proceso paralelo, que repercutirá en el tiempo efectivo de carrera de servicio y, por tanto, de cotización de los futuros miembros, y de planificación de personal de las Administraciones. El establecimiento de un límite máximo en la edad de acceso ha sido considerado discriminatorio tanto por la jurisprudencia del Tribunal Supremo como del Tribunal de Justicia de la Unión Europea, con mayores cautelas para este último.

\section{Bibliografía}

Agoués Mendizabal, Carmen (2017): «La discriminación por razón de la edad en el acceso a los cuerpos de policía. STJUE de 15 de noviembre de 2016, asunto C-258/15: Salaberría Sorondo", La Ley Unión Europea, núm. 45 (LA LEY 2029/2017).

Almonacid Lamelas, Víctor (2005): «El régimen jurídico aplicable a las Policías Locales: legislación y jurisprudencia (1)», El Consultor de los Ayuntamientos, núm. 24 (LA LEY 1749/2006).

Bastardo Yustos, Francisco Manuel (2004): «La situación administrativa de segunda actividad en la Policía Local. Especial referencia a la legislación de la Comunidad de Castilla-La Mancha», El Consultor de los Ayuntamientos, núm. 23 (LA LEY 5619/2005).

Blanco LaRA, María Luisa (2014): «La segunda actividad: una situación administrativa especial de los cuerpos de policía local», Revista Digital CEMCI, núm. 245, 3-41.

Calvo Ramírez, Clementino (1988): «Régimen de clases pasivas de los funcionarios del Estado", Revista de Seguridad Social, núm. 37, 117-206. 
De la Villa Gil, Luis Enrique (1971): Estudios sobre Seguridad Social de los funcionarios públicos, Madrid, Publicaciones de la Escuela Nacional de Administración Pública.

FERnÁndez FERnándeZ, Roberto (2009): «Racionalización y simplificación de los regímenes especiales de los funcionarios públicos. Clases Pasivas del Estado», en Fernández Domínguez, Juan José y Martínez Barroso, María de los Reyes: Las vías de integración y racionalización de los regímenes especiales, Madrid. Secretaría de Estado de Seguridad Social, en línea (26.IV.2017). www.seg-social.es/prdi00/groups/public/documents/binario/143938.pdf

FERnÁNDez Márquez, Óscar (2015): «Principio de no discriminación y edades máximas. A propósito de la STJUE de 13 de noviembre de 2014 (Vital Pérez), que declara contrario al ordenamiento comunitario el tope de edad de 30 ańos exigido para el ingreso en un Cuerpo de Policía Local», La Ley Unión Europea, núm. 24, 33-47 (LA LEY 2521/2015).

Fragoso Soldevila, Santiago (2017): «La Ertzaintza y los 35 años. Sentencia del Tribunal de Justicia (Gran Sala) de 15 de noviembre de 2016 (LA LEY 157199/2016). Asunto C-258/2015, Gorka Salaberría Sorondo v. Academia Vasca de Policía y Emergencias», Actualidad Administrativa, núm. 1 (LA LEY 9648/2016).

Gil Franco, Agustín Juan (2014): «Competencia local en materia de policía y régimen jurídico de los cuerpos de policía local», Tesis Doctoral Universidad Nacional de Educación a Distancia.

GonzÁlez Bustos, María Ángeles (2002): «Notas sobre la situación de segunda actividad en la regulación de la Policía Local de Castilla y León", El Consultor de los Ayuntamientos, núm. 13 (LA LEY 4135/2003).

López Aniorte, María Carmen (2017): «Límites a la proliferación del trabajo atípico y en fraude de ley en la Administración Pública», Estudios financieros. Revista de trabajo y seguridad social: Comentarios, casos prácticos: recursos humanos, núm. 411, 2017, 17 50.

Ortega Montoro, Rodrigo (2010): "La limitación de acceso por edad a los cuerpos de Policía Local y Bomberos desde el principio de igualdad de trato en el empleo», El Consultor de los Ayuntamientos, núm. 11 (LA LEY 4748/2010).

Palomar Olmeda, Alberto (2006): Función Pública. Madrid, Thomson Reuteres Aranzadi.

Parada Vázquez, Ramón y Fuentetaja Pastor, Jesús (2015): Derecho de la Función Pública. Madrid, Open Ediciones Universitarias.

PÉrez LuQue, Antonio (2005): La provisión y pérdida de los puestos de trabajo de las corporaciones locales, Madrid, Editorial El Consultor de los Ayuntamientos y de los Juzgados.

Entrena Cuesta, Rafael (1995): Curso de Derecho Administrativo Vol. I/2 Organización Administrativa. Madrid, Tecnos.

Rodríguez Escanciano, Susana (2008): «Los Regímenes Especiales de los funcionarios públicos: situación actual y perspectivas», Foro de Seguridad Social, núm. 20, 154-169.

Serrano Segura, José (2001): «Supuesto especial de jubilación anticipada para trabajadores de la Policía Local y Bomberos dependientes de los Ayuntamientos», El Consultor de los Ayuntamientos, núm. 13 (LA LEY 3967/2003).

Trayter Jimenez, Joan Manuel (2016): «La situación administrativa de segunda actividad aplicable a determinados cuerpos especiales de funcionarios», Revista Catalana de Dret Public, núm. 53, 182-197. 